\title{
What does valve, not myocardial LGE mean? Could it portend post-Ml emergence of mitral regurgitation?
}

Hari Bogabathina, Mark Doyle, Ronald B Williams, June A Yamrozik, Diane V Thompson, Robert W Biederman ${ }^{*}$

From 17th Annual SCMR Scientific Sessions

New Orleans, LA, USA. 16-19 January 2014

\section{Background}

Post-MI mitral regurgitation is thought to be due to passive, rather than active remodeling of mitral valve apparatus and relationship with other cardiac structures contributing to mitral regurgitation. Standard CMR late gadolinium enhancement (LGE) may be sensitive to non-myocardial pathology involving the mitral valve leaflets.

\section{Methods}

Presence or absence of MVE was noted in patients presenting for routine CMR with MI and non-MI indications requiring LGE. Chi square analysis was performed for non-contiguous variables and SPSS, Chicago software was utilized for statistical analysis. We hypothesize the presence of mitral valve enhancement (MVE) on LGE imaging in post-MI patients is associated with an increased incidence of MR.

\section{Results}

Patients (87; $\mathrm{M}=54, \mathrm{~F}=33)$ underwent LGE-CMR studies utilizing 1.5T GE (Milwaukee, WI) scanner with MultiHance (Bracco, Princeton, NJ) gadolinium contrast administration. LGE+ (present) in 68 and LGE- (absent) in 19 studies. Post-MI patterns of LGE+ in 51 and LGE- in 36 pts. MVE+ in 39, MVE- in 48. MR+ present in 67 and MR- in 20 studies. MVE was observed chiefly in post-MI patients (33 of 51; 65\%) and infrequently in non-post-MI patients $(6$ of $36 ; 17 \%) ; \chi 2=17.8, \mathrm{p}<0.001$, power $=$ 0.995 . Further, MR was present more frequently in patients with MVE (36 of 39; 92\%) compared to patients without MVE (31 or $48 ; 65 \%) ; \chi 2=7.8, \mathrm{p}=0.005$, power $=$ 0.814 (see Figure 1).

\section{Conclusions}

MVE is present in a large number of post-MI patients but rarely in non-post-MI patients. Post-MI patients

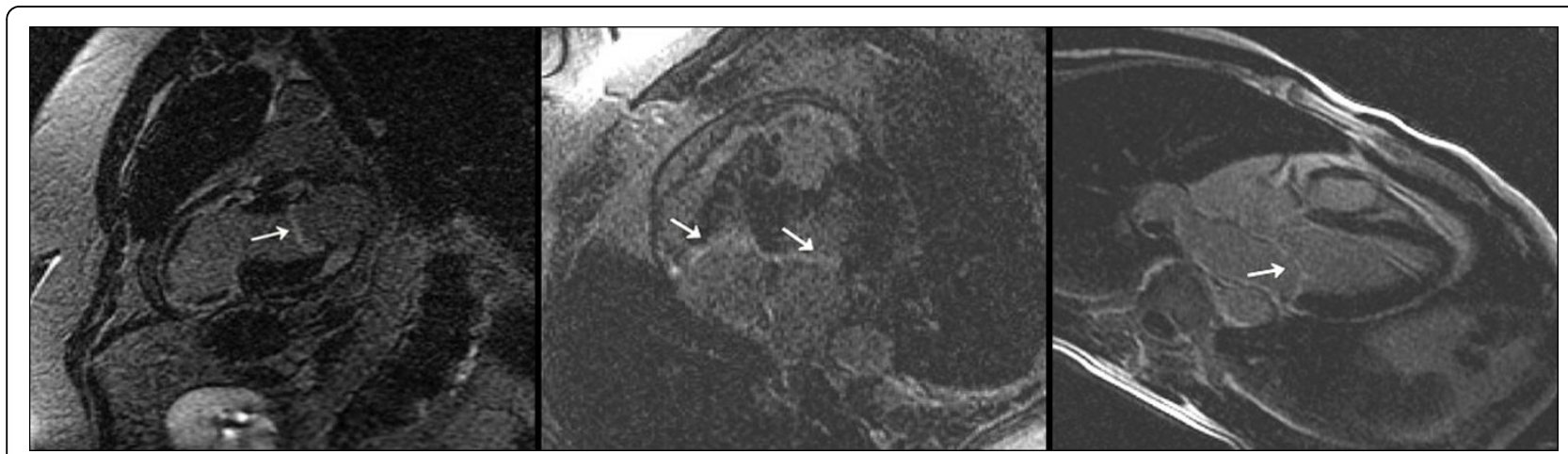

Figure 1 Examples of MVE.

Cardiac MRI, Allegheny General Hospital, Pittsburgh, Pennsylvania, USA 
with rather than without MVE are far more likely to have MR. These observations suggest a specific, as yet unknown, reactive process may contribute to mitral leaflet remodeling in post-MI patients potentially contributing to the increased incidence of MR in post-MI patients. Thus, active remodeling of the mitral valvar structure may be operative in conjunction with passive geometric LV remodling and collectively promote post-MI mitral regurgitation

\section{Funding}

Internal.

Published: 16 January 2014

doi:10.1186/1532-429X-16-S1-P98

Cite this article as: Bogabathina et al:: What does valve, not myocardial

LGE mean? Could it portend post-MI emergence of mitral

regurgitation? Journal of Cardiovascular Magnetic Resonance 2014

16(Suppl 1):P98.

Submit your next manuscript to BioMed Central and take full advantage of:

- Convenient online submission

- Thorough peer review

- No space constraints or color figure charges

- Immediate publication on acceptance

- Inclusion in PubMed, CAS, Scopus and Google Scholar

- Research which is freely available for redistribution

Submit your manuscript at www.biomedcentral.com/submit
C Biomed Central 